\title{
BIOÉTICA Y SALUD PÚBLICA: AL CRUCE DE LOS CAMINOS
}

\section{Christian Darras*}

\begin{abstract}
Resumen: En su desarrollo respectivo, tanto la ética médica y, luego, la bioética como la salud pública han llegado a un punto de encuentro. Este proceso se traduce en una puesta en tensión de los principios fundadores de la bioética, debido a las contradicciones que surgen entre lo individual y lo social. Sin embargo, la búsqueda de nuevos valores puede ayudar a enfocar esta aparente oposición. En este recorrido, la bioética trae consigo su valioso método de debate abierto y contradictorio, mientras la salud pública presenta una tradición de organización de las acciones sanitarias basada en conceptos sociales (solidaridad, responsabilidad, interculturalidad). Esto permite reflexionar, además, a propósito de las condiciones concretas del ejercicio de la bioética en los servicios de salud.
\end{abstract}

Palabras clave: Bioética, salud pública

\section{CROSSROADS OF BIOETHICS AND PUBLIC HEALTH}

\begin{abstract}
In their respective development, medical ethics, as well as public health, reached a crossing point. This process provokes a tension amongst the principles of medical ethics, due to the contradictions aroused between the individual and the social. Nevertheless, the search of new values can help to highlight this apparent opposition. In this manner, medical ethics brings its valuable method of open and contradictory debate, while public health shows a tradition of organization of health activities based on social concepts (solidarity, responsibility, intercultural focus). In addition, in this way, it is also possible to explore the actual conditions for the exercise of medical ethics in the field of health services.
\end{abstract}

Key words: Bioethics, public health

\section{BIOÉTICA E SAÚDE PÚBLICA: AO CRUZAR OS CAMINHOS}

Resumo: No seu respectivo desenvolvimento, tanto a ética médica e, em seguida, a bioética, como a saúde pública chegaram a um ponto de encontro. Este processo é traduzido por uma tensão dos princípios fundadores da bioética, devido às contradições que surgem entre o individual e o social. No entanto, a busca de novos valores pode ajudar a enfocar esta aparente oposição. Nesse transcurso, a bioética traz consigo seu valioso método de debate aberto e contraditório, enquanto a saúde pública apresenta uma tradição de organização das ações sanitárias baseada em conceitos sociais (solidariedade, responsabilidade, interculturalidade). Isto permite refletir, também, a propósito das condições concretas do exercício da bioética nos serviços de saúde.

Palavras-chave: Bioética, saúde pública

* Consultor Internacional Desarrollo Servicios de Salud OPS/OMS

Correspondencia: darrasc@chi.ops-oms.org 
El desarrollo de la ética médica ha estado marcado por sus vínculos estrechos con la práctica clínica(1). En esta relación se han ido definiendo valores o principios que permiten ordenar el debate y orientar las decisiones: ellos son los de "no maleficencia", "beneficencia", "autonomía" y "justicia". Cuando se aplican a los individuos estos principios no se oponen entre sí; al contrario, se complementan en una mirada amplia del respeto que merecen las personas en el momento de buscar y recibir atención médica. En este sentido, han alimentado las iniciativas legales de protección de los derechos de los pacientes(2).

La salud pública, por su esencia, va más allá del individuo. Existen acepciones variadas de la salud pública, pero todas se refieren al entorno que rodea a los individuos y toman en cuenta su familia, su comunidad y la sociedad en general. Dentro de esta visión común se pueden identificar de manera esquemática dos polos, que calificaríamos como minimalista y maximalista.

La mirada minimalista tiende a considerar que el campo de la salud pública debe limitarse a medidas, generalmente de promoción y prevención, que no interesan al libre mercado de la atención médica. Debe centrarse en los llamados "bienes públicos", es decir, aquellos para los cuales se reúnen las condiciones de obligatoriedad y de no rivalidad. Son bienes al beneficio de los cuales uno no puede escapar, pero cuyo uso no reduce la cantidad disponible para otros. Un ejemplo clásico de este tipo de bienes es el aire que respiramos: presenta cierta calidad, independiente de nuestra voluntad individual de modificarla, y lo podemos consumir sin afectar al resto de la población.

En el enfoque maximalista se piensa que, por naturaleza, no existen elementos del tema de salud que no tengan repercusiones sobre los otros y, entonces, todo es salud pública. Si bien existen relaciones individuales entre médicos y pacientes, las condiciones en las cuales se desenvuelven son determinadas por $-\mathrm{y}$ determinan a su vez- las demás relaciones entre médicos y pacientes. En este sentido, el pago de la atención médica no se limita a una simple transacción económica entre dos personas, sino que afecta la cantidad y la calidad de las consultas que se pueden realizar en una sociedad, en función de las relaciones de poder que prevalecen en ella.

De cualquier modo, la salud pública transforma el cuerpo individual, como objeto de la salud, en un cuerpo socializado y en un cuerpo social normalizado. Se pasa del tratamiento de la enfermedad a la planificación de la salud(3). Como consecuencia, la salud pública introduce una tensión entre los cuatro principios básicos de la ética(4). Por ejemplo, el principio de no maleficencia que sustenta la prohibición de fumar en espacios públicos, para no comprometer la salud de los no fumadores, se opone al principio de autonomía, que lleva a tomar en cuenta la opción de los fumadores para dar curso a una necesidad propia. En un modo similar, la reciente epidemia de SARS volvió a manifestar que una medida de cuarentena, decidida bajo un principio de protección del conjunto de la sociedad, limita la libertad de movimientos de las personas afectadas y, eventualmente, las estigmatiza.

Hay que señalar que en el mismo campo de la ética esta disyuntiva empezó a apreciarse con fuerza con el desarrollo de las investigaciones, ya que su justificación se sustenta no en el provecho directo de la persona atendida, sino en los beneficios futuros para la humanidad. Éstos, además, no son ni automáticos ni inmediatos. En efecto, puede resultar que la investigación fracase en su propósito de hallar un nuevo tratamiento y, en caso de que lo encontrase, la 
aplicación demorará siempre. Son estas contradicciones las que llevaron, justamente, a elaborar pautas éticas para la investigación biomédica en seres humanos y a precisar nuevas nociones, como la confidencialidad, el consentimiento informado o el conflicto de intereses(5). Además, a partir de allí se acuñó el término "bioética". En el mismo orden de ideas, la Declaración de Erice, elaborada bajo el auspicio del Centro Colaborador de la OMS de Uppsala, indica que las informaciones relativas a la seguridad de los medicamentos deben servir a la salud pública. Por lo tanto, no pueden ser retenidas bajo el pretexto de la confidencialidad o de la defensa de beneficios particulares(6). En esta perspectiva, no solamente la investigación per se debería ser sujeto de escrutinio ético, sino el uso que se da o no al conocimiento conseguido. Para tal fin se acuño el término de "mal praxis científica", que contempla la falsificación deliberada de datos así como la falta de publicación de los resulta$\operatorname{dos}(7)$.

Esta tensión, propia de la aplicación de la bioética a la salud pública, está en el centro de la definición de las políticas públicas en salud. La podemos visualizar con el tema de los estilos de vida saludable. Por un lado, representan un esfuerzo para mejorar el estado de salud de la población, además de precautelar la defensa del dinero público con la disminución de la carga de enfermedades futuras. Pero, por otro, pueden ser vistos como la generalización de una cultura sanitaria uniforme, poco cuidadosa de las opiniones personales, para no hablar de la imposición de un modelo sanitario de conducta. Así, el diagnóstico de un nivel elevado de colesterol conlleva una pesada carga de valoración moral(8) ¿Cuál es, entonces, el equilibrio que es preciso mantener entre el intervencionismo benevolente y la responsabilidad ciudadana?
Ahora bien, esta manera de enfocar la oposición entre principios éticos $\mathrm{y}$, más concretamente, entre beneficencia para unos y nomaleficencia para otros, mantiene una visón de las personas como "objetos" de las intervenciones de salud. Unos aprovechan las intervenciones de las cuales otros sufren, pero ninguno tiene capacidad de actuar sobre ellas. Sin embargo, el aparente antagonismo entre interés individual e interés colectivo puede empezar a superarse si consideramos que las personas son "sujetos", es decir, dotadas de capacidad de análisis y toma de decisión frente, precisamente, a este antagonismo. Dicho de otra manera, cuando las personas pueden reflexionar sobre el impacto de las acciones sobre su salud como también sobre la de los demás, empezando por sus parientes y vecinos, logran combinar intereses de diferente índole. Para eso hacen uso de nuevos valores, como los de responsabilidad y solidaridad.

Existen varias acepciones del término "responsabilidad". No obstante, tienen en común el reconocimiento de la vulnerabilidad de ciertos sujetos que insinúan una necesidad de amparo por parte de otros. Para algunos sería más preciso hablar de ética de protección, recuperando el origen del vocablo "ética", cuyo sentido primero es de "refugio y protección(9)". En cuanto a la solidaridad, también existen diferentes teorías que la sustentan, desde el utilitarismo hasta el comunitarismo. Una conclusión general sería que los seres humanos no son tan poco cooperativos como se podría esperar. Actúan como si cada uno entendiese que es más provechoso cooperar para el interés del grupo $\mathrm{y}$, por ende, para cada integrante de esa colectividad(10). En todos los casos ponen en juego la noción de identidad colectiva, la misma que delimita el espacio de la solidaridad. Por oposición, los que no son reconocidos como pares van poblando el universo de los excluidos. En esta perspectiva, la historia de la humanidad 
podría escribirse desde los avances y retrocesos en la delimitación de este universo. Como última etapa, la globalización se caracteriza por una dinámica de inclusión acelerada para unos y de segregación marcada para otros.

Otra característica de la salud pública es la aparición de nuevos actores que intervienen en la relación médico-paciente y que están encargados de funciones propias del sistema en su conjunto, como la regulación, el financiamiento, la evaluación o la formación. Además, el costo creciente de la tecnología médica introduce una separación entre los dueños de la infraestructura (capaces de realizar las inversiones necesarias) y los médicos, que se transforman en sus empleados. Para responder a esta situación, los mismos médicos se organizan en gremios que defienden la profesión en su conjunto(11). En síntesis, las organizaciones representan un peso cada vez mayor en la práctica de la medicina, lo que conduce a la pregunta: ¿existe una ética de las organizaciones que sea más que la suma de las éticas profesionales? ¿Existe lo que Jennings, citado por Thompson, llama critical ethics(1)? Según este concepto, los valores sociales y las tendencias históricas van conformando los arreglos institucionales, confiriéndoles un reconocimiento genuinamente público o cívico.

Las consideraciones anteriores llevan a renovar la mirada sobre las relaciones entre bioética y salud pública, en un enriquecimiento mutuo. En un sentido, la bioética trae consigo un contenido y un modelo. El primero se refiere a los valores centrales que va identificando; el segundo, al proceso de debate abierto y contradictorio que promueve(12). Dicho de otro modo, la bioética permite un lenguaje y una lectura comunes entre los actores. En este enfoque, la bioética no debe confundirse con el derecho o con la religión. Mientras la bioética se basa en la deliberación, proponiendo valo- res que puedan sostener las conductas de las personas y de las organizaciones, el derecho y la religión son del orden de la prescripción, en el ámbito público para el uno y en el privado para la otra. La bioética permite a la salud pública, entonces, encontrar su camino entre la ley y la moral.

Al revés, la salud pública puede, por su parte, enriquecer a la bioética proponiendo nuevos valores ligados al enfoque social de la medicina(13). Ya se citaron la responsabilidad y la solidaridad. Se podría agregar la pertinencia, entendida como la necesidad de desarrollar intervenciones de salud pública que tengan una eficacia demostrada con un costo razonable. Asimismo, se podría mencionar el enfoque intercultural. No se trata solamente de la no discriminación, no se limita al respeto de las otras culturas, sino que es el reconocimiento de que cada cultura tiene su propia racionalidad y subjetividad. No habría unas culturas científicas y otras mágicas, sino que todas son, a la vez, científicas y mágicas. Otro valor ligado al quehacer de las organizaciones es el abordaje multidisciplinario de la atención en salud. La cooperación entre integrantes de los equipos de salud no es solamente deseable, sino que se convierte en una exigencia para asegurar una mejora de la calidad. Todos los que trabajan en este sector deberían aprender continuamente los unos de los otros.

Asimismo, una mirada desde la salud pública permite "revisitar" algunos temas clásicos de la bioética, como los ligados al respeto de la vida (fecundación artificial, muerte asistida o manipulación del genoma). En este caso, una de las preguntas que se puede hacer es, por ejemplo, la del acceso a estas nuevas prácticas. En efecto, uno de los aspectos de la bioética del desarrollo científico es, también, la posibilidad de un usufructo equitativo de sus beneficios y no solamente la protección contra sus 
riesgos(14). ¿Para qué investigar las oportunidades del tratamiento por células embrionarias o de los alimentos transgénicos si no estarán disponibles para todos los que las van a necesitar? ¿Vamos a movilizar los recursos bioéticos, limitados como otros, cada vez más hacia las innovaciones tecnológicas o a preservar el estudio de aspectos menos llamativos, pero más comunes, como la calidad de la atención dispensada a la fecha, su sustentabilidad financiera y su adecuación a las aspiraciones de los beneficiarios(15)? Esta mirada permitiría evitar, tal vez, que la bioética vea limitado su rol a legitimar, a posteriori, las evoluciones que el mercado o la sociedad imponen.

Amén de esta relación de tipo conceptual entre bioética y salud pública existe otra, más práctica. Se refiere a las consecuencias de la política de salud pública sobre las condiciones concretas de desempeño de los trabajadores de salud y de la ética de su actuación. En efecto, de la manera en que estén organizados los servicios de salud se desprenden, por lo menos en parte, los incentivos o los obstáculos a una aplicación de los principios de la bioética. Encontramos un ejemplo en la cuestión del estigma y de la discriminación por el VIH/SIDA en el sector $\operatorname{salud}(16)$. Sin negar la importancia de los comportamientos individuales, es también cierto que, dentro de las causas para tales casos, se puede identificar la falta de un ambiente y de una infraestructura que satisfagan las necesidades de los pacientes y de los trabajadores de salud. Frente al agotamiento, a la impotencia y al rechazo por los otros trabajadores del sector, los encargados de atender a las personas con VIH/SIDA presentan menos capacidad de resistencia a conductas de estigma y discriminación. La bioética no escapa al escenario vívido de su ejercicio.

Este aporte mutuo constituye, de por sí, una contribución al fomento de la cultura democrá- tica en salud. En el momento en que los espacios tradicionales de democracia, como son el parlamento, los partidos políticos o los sindicatos, sean considerados con más escepticismo por la sociedad, será importante abrir nuevos espacios, ligados a las preocupaciones ciudadanas. Al respecto, se puede observar que el campo de la atención médica se ha convertido en uno de los espacios más activos de debate dentro de la sociedad. En el caso del VIH/SIDA, es de particular relevancia la participación activa de las personas que viven con el virus. En este sentido, el hospital, como paradigma de los espacios de poder que atraviesan el sector de la salud, podría constituir un especial campo de aplicación de la democracia en nuestras sociedades modernas(17).

En conclusión, por su desarrollo propio, tanto la bioética como la salud pública están llegando a un punto de encuentro. Por lo tanto, no es extraño observar que estas relaciones son el objeto de un interés creciente en las esferas tanto políticas como académicas(18). Una mirada cruzada nos da la posibilidad de avanzar hacia una identificación de problemas éticos propios de la salud pública, es decir, a la relación entre individuos y sociedad, entre lo subjetivo y lo objetivo. Basándose en la clasificación propuesta por Massé(19), algunos ejemplos de estos problemas podrían ser: a) la persuasión y la coerción en las intervenciones de salud pública; b) la identificación de riesgos, la estigmatización y la discriminación social; c) la justicia social, la discriminación positiva y el mérito; d) la certitud científica, la probabilidad estadística y la precaución; e) la responsabilidad individual en acciones colectivas, y f) las condiciones concretas de la práctica de la bioética en los servicios de salud. Esta identificación permitiría, por su parte, precisar el nivel de desarrollo de esta disciplina en salud pública, las falencias eventuales, las respuestas aportadas y sus modalidades. 
Al respecto, se podría preguntar si la palabra "bio"ética es la más apropiada cuando se entra en el terreno de la salud pública. En efecto, induce a pensar en términos biológicos más que en términos sociales, en prácticas individuales más que de organizaciones, en problemas de vida y muerte más que de justicia y democracia. Sin embargo, como en todo campo naciente, avanzar con prudencia parece ser una sana y sabia recomendación. El entusiasmo de la innovación puede resultar en daños no previstos, precisamente porque el campo es desconocido. Un espíritu de investigación, una buena dosis de imaginación y un debate permanente y abierto deberían conformar útiles resguardos.

\section{Referencias}

1. Thompson A, Robertson A, Upshur R. Public Health Ethics: Towards a Research Agenda. Acta Bioethica 2003; $2: 157-63$.

2. Iliev D, Vienonen M. Patients' Rights Development in Europe. World Health Organization. Regional Office for Europe; 1998.

3. Hours B. Pour une anthropologie de la santé. In: Systèmes et politiques de santé. Paris: Karthala; 2001.

4. Coughlin SS, Soskolone CL, Goodman KW. Cases Studies in Public Health Ethics. Washington DC: American Public Health Association; 1997.

5. Consejo de Organizaciones Internacionales de las Ciencias Médicas (CIOMS). Pautas éticas internacionales para la investigación biomédica en seres humanos. Ginebra: CIOMS; 2002.

6. La déclaration d'Eurice. Sur la communication d'informations concernant la sécurité d'emploi des médicaments. Rev Prescr 1998;18 (187): 599.

7. Chalmers I. La falta de publicación de los resultados de la investigación como malpraxis científica. En: Aspectos metodológicos, éticos y prácticos en ciencias de la salud. Washington, D.C.: Publicación Científica 550. OPS; 1994.

8. Massé R. La santé publique comme projet politique et projet individuel. In: Systèmes et politiques de santé. Paris: Karthala; 2001.

9. Schramm FR, Kottow M. Principios bioéticos en salud pública: limitaciones y propuestas. Cadernos de Saúde Pública 2001; 17 (4): 949-56.

10. Gillinson S. Why Cooperate? A Multi-Disciplinary Study of Collective Action. UK Overseas Development Institute. Working Paper 234. February 2004.

11. Scavino J. Panorama de organizaciones de profesionales y trabajadores de la salud en las Américas. Washington, D.C.: Serie Desarrollo de Recursos Humanos HR-35 OPS; 2004.

12. Lolas F. Public Health and Social Justice: Toward ethical sustainability in healthcare and research. Acta Bioética 2003; 2:189-94.

13. Chadwick R, Berg K. Solidarity and equity: new ethical frameworks for genetic databases. Nature Reviews Genetics 2001; 2: 318-21.

14. (Editorial). Facts versus ideology in the cloning debate. The Lancet 2004; 363; 581. 
15. La Chronique de la Ligue des droits de l'Homme. Bruxelles. $\mathrm{N}^{\circ}$ 101: 6.

16. Organización Panamericana de la Salud (OPS). Comprensión y respuesta al estigma y a la discriminación por el VIH/SIDA en el sector salud. Washington: OPS; 2003.

17. Touraine A. Qu'est-ce que la démocracie? Paris: Fayard; 1994.

18. (Editorial). Acta Bioethica 2003; 2:151-5.

19. Massé R. Ethique et santé publique: enjeux, valeurs et normativité. Québec: Presses de l'Université Laval; 2003. 